\title{
The patient-urologist relationship in the COVID-19 era and beyond
}

\author{
Hiren V. Patel, MD, PhD; Arnav Srivastava, MD, MPH; Alexandra L. Tabakin, MD; Thomas L. Jang, MD, MPH; \\ Eric A. Singer, MD, MA, MS, FACS
}

Section of Urologic Oncology, Rutgers Cancer Institute of New Jersey and Rutgers Robert Wood Johnson Medical School, New Brunswick, New Jersey, United States

Cite as: Can Urol Assoc J 2020;14(6):E271-3. http://dx.doi.org/10.5489/cuai.6688

$\mathrm{T}$ he world has rapidly altered all aspects of its normal activities to control COVID-19, including how patients and their healthcare providers interact. The medical community has remained at the forefront of these adaptations to provide the highest level of care for COVID-19 and non-COVID-19 patients. We have witnessed unforgettable examples of the heroism, humanism, and compassion that are the foundation of a healing relationship between patient and physician in an environment with strapped resources, such as personal protective equipment, ventilators, and staffing. While the scope of the pandemic remains to be determined, this presents an opportunity to understand the changes that the field of urology has endured and its lasting impact on the patient-urologist relationship.

As cases approach 5 million persons worldwide (at present time), many urologists have been deployed to provide care for COVID-19 patients. ${ }^{1}$ The urology community quickly developed pathways to triage high-risk and emergent urology cases while preserving resources and mitigating risk. ${ }^{2,3}$ In addition to explaining the standard risks and benefits of an operation, urologists have engaged in new dimensions of shared decision-making - weighing the risk of delaying treatment with the risk of COVID-19 exposure. As many urological patients are older with multiple comorbidities, this cohort may be more susceptible to develop severe sequelae and mortality from COVID-19. As deferring surgery is not a "one-size-fits-all" strategy, urologists should exercise clinical judgement regarding which patients require urgent interventions vs. those who can be rescheduled. Great care must be taken to ensure that those who have deferred care must not be lost to followup due these postponements. All surgical specialties will have an intensifying backlog of office visits and operative cases that will need prioritization when elective cases resume and office hours normalize. A systematic model for prioritizing deferred cases will be necessary, as operating rooms and clinics will be working with limited time and space (Appendix).

Physicians across multiple specialties have quickly adopted telemedicine as part of the social distancing strat- egy. To this end, in the U.S, the Centers of Medicare and Medicaid Services (CMS) expanded the telehealth coverage and expanded supervision of inpatient visits to advanced practice providers for Medicare patients. Similarly, European and Asian countries have expanded their use of telemedicine in an effort to provide continued access to healthcare services. ${ }^{4}$ Telemedicine, now being used across many urological subspecialties, can reduce unnecessary ancillary costs and allow the continuation of office-based urological care. ${ }^{5,6}$ However, patient education level, access to technology, costs, and reimbursement uncertainties are key barriers for universal adoption of telemedicine. ${ }^{7}$ Telehealth remains a double-edge sword, as it intends to expand access to care, but may also disenfranchise some patients. Those who lack technological proficiency and resources, such as the elderly and patients with lower socioeconomic status, may still be unable to receive reliable telehealth services, which may affect their health outcomes. System-level innovations will be necessary to create infrastructure and an environment where the most vulnerable patients in urology have the appropriate access to care.

The COVID-19 pandemic has changed how patients and urologists-in-training interact. Urology trainees have implemented telemedicine visits. While human touch is still a vital part of the art of healing, trainees are learning how to triage acute presentations without being physically present amid this pandemic. The patient-urologist relationship is one that is complex and needs time to develop. Under the current circumstance, trainees have to learn advanced communication skills with limited time and feedback, both of which are needed to practice and reinforce communication skills in clinical situations. Moreover, trainees face an uphill battle in terms of maintaining robust clinical volume and didactic programs. While efforts to augment didactics through virtual platforms have been successful, this global crisis has stolen vital training for many residents. In an era where telehealth will likely be welcomed, teaching residents to adopt this new interface of healthcare to effectively provide for the most vulnerable urological patients will require a careful and systematic effort. 
The increased financial burden for urologists and hospitals threatens access to care for many urology patients during and after this crisis. An estimated $\$ 362$ billion to $\$ 1.45$ trillion in charges will arise from COVID-19 patient care in U.S. ${ }^{8}$ Even with a $20 \%$ increase in reimbursement, there is a predicted $\$ 6000-8000$ loss per case for the hospital on the treatment of COVID-19 patients..$^{9}$ The cancellation of elective cases decreases a large portion of revenue, further widening the gap between costs and revenue for the hospital. Under these financial pressures, many hospitals and urology offices may be forced to reduce labor costs, furlough employees, and possibly reduce services for the under-insured and uninsured. In the U.S, the passage of the Coronavirus Aid, Relief, and Economic Security Act intends to provide $\$ 376$ billion to small businesses and workers through several temporary programs, including paycheck protection programs, express loans, and debt relief programs to help offset the financial disruption. Novel strategies supported by federal entities and public-private partnerships may mitigate this financial strain and ensure that access to care is maintained for patients with new and existing urological conditions.

For many patients, standard therapies have been exhausted and they may benefit from participation in clinical trials. The pandemic has decreased clinical trial participation, reshaped current trial portfolios, and may even alter study outcomes. As the possibility for a second wave of infection remains unknown, urologists will need to reassess nononcology and oncology patients for clinical trial participation given interim disease progression and possible infection risks. This is especially true in the urologic oncology population, where patients often require multiple clinic visits, adjunct therapies, and outpatient testing. ${ }^{10}$

Our health system will inevitably face future crises, and we must use the lessons learned during the COVID-19 pandemic to ensure that we respond appropriately. Continued efforts to provide the highest level of urological care in the post-COVID era will require a balanced and purposeful determination that sustains the primacy of the patient-urologist relationship within a continually evolving healthcare landscape.

Competing interests: Dr. Singer receives research support from Astellas/Medivation. The remaining authors report no competing personal or financial interests related to this work.

Funding: This work is supported by a grant from the National Cancer Institute (P30CA072720).

\section{References}

1. Chan MC, Yeo SEK, Chong YL, et al. Stepping forward: Urologists' efforts during the COVID-19 outbreak in Singapore. Eur Urol 2020. [Epub ahead of print]. https://doi.org/10.1016/i.eururo.2020.03.004

2. Proietti S, Gaboardi F, Giusti G. Endourological stone management in the era of the COVID-19. Eur Urol 2020. [Epub ahead of print]. https://doi.org/10.1016/i.eururo.2020.03.042

3. Stensland KS, Morgan T, Moinzadeh A, et al. Considerations in the triage of urologic surgeries during the COVID-19 pandemic. Eur Urol 2020. [Epub ahead of print]. https://doi.org/10.1016/i. eururo.2020.03.027

4. Connor MJ, Winkler M, Miah S. COVID-19 pandemic - is virtual urology clinic the answer to keeping the cancer pathway moving? BJU Int 2020. [Epub ahead of print]. https://doi.org/10.1111/bju.15061

5. Finkelstein JB, Cahill D, Young K, et al. Telemedicine for pediatric urologic postoperative care is safe, convenient, and economical. J Urol 2020:101097JU0000000000000750. https://doi.org/10.1097/ JU. 0000000000000750

6. Zholuder V, Safir IJ, Painter MN, et al. Comparative cost analysis: Tele-urology vs. conventional face-to-face clinics. Urology 2018;113:40-4. https://doi.org/10.1016/i.urology.2017.07.034

7. Scott Kruse C, Karem P, Shifflett K, et al. Evaluating barriers to adopting telemedicine worldwide: A systematic review. J Telemed Telecare 2018;24:4-12. https://doi.org/10.1177/1357633X16674087

8. Health F. COVID-19: The projected economic impact of the COVID-19 pandemic on the US healthcare system. 2020. Available at: https://s3.amazonaws.com/media2.fairhealth.org/brief/asset/COVID19\%20 $\% 20$ The $\% 20$ Projected\%20Economic $\% 20$ Impact $\% 20$ of $\% 20$ the $\% 20$ COVID-19\%20Pandemic\%20 on\%20the\%20US\%20Healthcare\%20System.pdf. Accessed May 21, 2020.

9. Technology SD. Report: Hospitals face massive losses on COVID-19 cases even with proposed increase in federal reimbursement. 2020. Availablee at: https://www.stratadecision.com/blog/report-hospitalsface-massive-losses-on-covid-19-cases-even-with-proposed-increase-in-federal-reimbursement/. Accessed May 21, 2020

10. Liang W, Guan W, Chen R, et al. Cancer patients in SARS-CoV-2 infection: A nationwide analysis in China. Lancet Oncol 2020;21:335-7. https://doi.org/10.1016/S1470-2045(20)30096-6

Correspondence: Dr. Eric A. Singer, Section of Urologic Oncology, Rutgers Cancer Institute of New Jersey and Rutgers Robert, New Brunswick, NJ, United States; eric.singer@rutgers.edu 


\section{APPENDIX. COVID-19 resources \\ Resources for restarting elective surgeries \\ - Joint statement on restarting elective surgeries after COVID-19 pandemic ${ }^{11}$ \\ Resources for triaging cases \\ - Endourology cases ${ }^{2,12-14}$ \\ - Urologic oncology cases $^{12-15}$ \\ - Pediatric cases ${ }^{14,16}$ \\ Resources for urological oncology patients \\ - Guideline for cancer patients during COVID-19 pandemic ${ }^{10,17-20}$ \\ - Outcomes for cancer patients during COVID-1910}

\section{References}

1. Chan MC, Yeo SEK, Chong YL, et al. Stepping forward: Urologists' efforts during the COVID-19 outbreak in Singapore. Eur Urol 2020. [Epub ahead of print]. https://doi. org/10.1016/j.eururo.2020.03.004

2. Proietti S, Gaboardi F, Giusti G. Endourological stone management in the era of the COVID-19. Eur Urol 2020. [Epub ahead of print]. https://doi.org/10.1016/j. eururo.2020.03.042

3. Stensland KS, Morgan T, Moinzadeh A, et al. .Considerations in the triage of urologic surgeries during the COVID-19 pandemic. Eur Urol 2020. [Epub ahead of print]. https:// doi.org/10.1016/j.eururo.2020.03.027

4. Connor MJ, Winkler M, Miah S. COVID-19 pandemic - is virtual urology clinic the answer to keeping the cancer pathcrway moving? BJU Int 2020. [Epub ahead of print] https://doi.org/10.1111/bju.15061

5. Finkelstein JB, Cahill D, Young K, et al. Telemedicine for pediatric urologic postoperative care is safe, convenient, and economical. $J$ Urol 2020:101097JU0000000000000750. https://doi.org/10.1097/JU.00000000000000750

6. Zholudev V, Safir IJ, Painter MN, et al. Comparative cost analysis: Tele-urology vs. conventional face-to-face clinics. Urology 2018;113:40-4. https://doi.org/10.1016/j. urology.2017.07.034

7. Scott Kruse $C$, Karem P, Shifflett $K$, et al. Evaluating barriers to adopting telemedicine worldwide: A systematic review. J Telemed Telecare 2018;24:4-12. https://doi. org/10.1177/1357633X16674087

8. Health F. COVID-19: The projected economic impact of the COVID-19 pandemic on the US healthcare system. 2020. Available at: https://s3.amazonaws.com/media2.fairhealth org/brief/asset/COVID-19\%20-\%20The\%20Projected\%20Economic\%20Impact $\% 20$ of $\% 20$ the $\% 20$ COVID-19\%20Pandemic\%20on\%20the $\% 20$ US\%20Healthcare\%20System.pdf. Accessed May 21, 2020.

9. Technology SD. Report: Hospitals face massive losses on COVID-19 cases even with proposed increase in federal reimbursement. 2020. Available at: https://www. stratadecision.com/blog/report-hospitals-face-massive-losses-on-covid-19-cases-evenwith-proposed-increase-in-federal-reimbursement/. Accessed May 21, 2020

10. Liang W, Guan W, Chen R, et al. Cancer patients in SARS-CoV-2 infection: A nationwide analysis in China. Lancet Oncol 2020:21:335-7. https://doi.org/10.1016/S14702045(20)30096-6

11. Surgeons ACo, Anesthesiologists ASo, Nurses AopR, Association AH. Joint Statement: Roadmap for Resuming Elective Surgery after COVID-19 Pandemic. 2020. Available at: https://www.asahq.org/about-asa/newsroom/news-releases/2020/04/joint-statement-onelective-surgery-after-covid-19-pandemic. Accessed May 212020.

12. Goldman HB, Haber GP. Recommendations for tiered stratification of urologic surgery urgency in the COVID-19 era. J Urol 2020:101097JU0000000000001067. https://doi. org/10.1097/JU.0000000000001067

13. Simonato A, Giannarini G, Abrate A, et al. Pathways for urology patients during the COVID-19 pandemic. Minerva Urol Nefrol 2020. [Epub ahead of print].

14. Desouky E. Urology in the era of COVID-19: Mass casualty triage. Urol Practice 2020. [Epub ahead of print]. https://doi.org/10.1097/UPJ.0000000000000152

15. Campi R, Amparore D, Capitanio U, et al. Assessing the burden of non-deferrable major uro-oncologic surgery to guide prioritisation strategies during the COVID-19 pandemic: Insights from three Italian high-volume referral centers. Eur Urol 2020. [Epub ahead of print]. https://doi.org/10.1016/j.eururo.2020.03.054

16. Spinoit A-F, Haid B, Hiess $M$, et al. Impact of the COVID-19 pandemic on pediatric urology practice in Europe: A reflection from the European Association of Urology Young Academic Urologists. Eur Urol 2020. [Epub ahead of print]. https://doi. org/10.1016/j.eururo.2020.04.019

17. Kutikov A, Weinberg DS, Edelman MJ, et al. A war on two fronts: Cancer care in the time of COVID-19. Ann Intern Med 2020. [Epub ahead of print]. https://doi.org/10.7326/ M20-1133

18. Burki TK. Cancer guidelines during the COVID-19 pandemic. Lancet Oncol 2020. [Epub ahead of print]. https://doi.org/10.1016/S1470-2045(20)30217-5

19. Pietrantonio F, Garassino MC. Caring for patients with cancer during the COVID-19 outbreak in Italy. JAMA Oncol 2020. [Epub ahead of print]. https://doi.org/10.1001/ jamaoncol.2020.1426

20. Marron JM, Joffe S, Jagsi R, et al. Ethics and resource scarcity: ASCO recommendations for the oncology community during the COVI-19 pandemic. J Clin Oncol 2020. [Epub ahead of print]. https://doi.org/10.1200/JCO.20.00960

\section{Resources for urology practices}

- Challenges to urology practices ${ }^{1,14,21-24}$

- Telemedicine usage $\mathrm{e}^{4,25-27}$

\section{Resources for residency restructuring}

- Surgical department restructuring 28,29

- Urological department restructuring ${ }^{30-32,45}$

- Residency selection process ${ }^{33}$

Health delivery during COVID-19 pandemic

- Disparity of care delivered to non-COVID patients ${ }^{34-36}$

- Surgeon's dilemma during COVID-1937,38

- Effect on healthcare workers ${ }^{39-44}$

21. Ahmed K, Hayat S, Dasgupta P. Global challenges to urology practice during COVID-19 pandemic. BJU Int 2020. [Epub ahead of print]. https://doi.org/10.1111/bju.15082 22. Ficarra V, Novara G, Abrate A, et al. Urology practice during COVID-19 pandemic. Minerva Urol Nefrol 2020. [Epub ahead of print].23. Nowroozi A, Amini E. Urology practice in the time of COVID-19. Urol J 2020. [Epub ahead of print].

24. Puliatti S, Eissa A, Eissa R, et al. COVID-19 and urology: A comprehensive review of the literature. BJU Int 2020. [Epub ahead of print]. https://doi.org/10.1111/bju.15071

25. Boehm K, Ziewers S, Brandt MP, et al. Telemedicine online visits in urology during COVID-19 pandemic - potential, risk factors, and patients' perspective. Eur Urol 2020. [Epub ahead of print]. https://doi.org/10.1016/j.eururo.2020.04.055

26. Gadzinski AJ, Ellimoottil C, Odisho AY, et al. Implementing telemedicine in response to the 2020 COVID-19 pandemic. J Urol 2020:101097JU0000000000001033. https://doi. org/10.1097/JU.0000000000001033

27. Karim JS, Hachach-Haram N, Dasgupta P. Bolstering the surgical response to COVID-19: How virtual technology will save lives and safeguard surgical practice. BJU Int 2020. [Epub ahead of print]. https://doi.org/10.1111/bju.15080

28. Nassar AH, Zern NK, Mclntyre LK, et al. Emergency restructuring of a general surgery residency program during the coronavirus disease 2019 pandemic: The University of Washington experience. JAMA Surg 2020. [Epub ahead of print]. https://doi.org/10.1001/ jamasurg.2020.1219

29. Zarzaur BL, Stahl CC, Greenberg JA, et al. Blueprint for restructuring a department of surgery in concert with the healthcare system during a pandemic: The University of Wisconsin experience. JAMA Surg 2020. [Epub ahead of print]. https://doi.org/10.1001/ jamasurg.2020.1386

30. Vargo E, Ali M, Henry F, et al. Cleveland Clinic Akron General Urology Residency Program's COVID-19 experience. Urology 2020. [Epub ahead of print]. https://doi.org/10.1016/j. urology.2020.04.001

31. Porpiglia $F$, Checcucci $E$, Amparore $D$, et al. Slowdown of urology residents' learning curve during COVID-19 emergency. BJU Int 2020. [Epub ahead of print]. https://doi.org/10.1111/ bju. 15076

32. Amparore D, Claps F, Cacciamani GE, et al. Impact of the COVID-19 pandemic on urology residency training in Italy. Minerva Urol Nefrol 2020. [Epub ahead of print].

33. Gabrielson AT, Kohn TP, Clifton MM. COVID-19 and the urology match: Perspectives and a call to action. J Urol 2020:101097JU0000000000001037. https://doi.org/10.1097/ JU.0000000000001037

34. Kittleson MM. The invisible hand - medical care during the pandemic. N Engl J Med 2020. [Epub ahead of print]. https://doi.org/10.1056/NEJMp2006607

35. Krumholz HA. Where have all the heart attacks gone? The New York Times: The New York Times Company; 2020.

36. Lewis MA. Between scylla and charybdis - oncologic decision-making in the time of COVID-19. N Engl J Med 2020. [Epub ahead of print]. https://doi.org/10.1056/ NEJMp2006588

37. Wang $\mathrm{H}, \mathrm{Wu} \mathrm{J}$, Wei $\mathrm{Y}$, et al. Surgical volume, safety, drug administration, and clinical trials during COVID-19: Single-center experience in Shanghai, China. Eur Urol 2020. [Epub ahead of print]. https://doi.org/10.1016/j.eururo.2020.04.026

38. Angelos P. Surgeons, ethics, and COVID-19: Early lessons learned. J Am Coll Surg 2020. [Epub ahead of print]. https://doi.org/10.1016/j.jamcollsurg.2020.03.028

39. Corley J. Doctors in training are dying, and we are letting them down. Forbes; 2020

40. Greenberg N, Docherty M, Gnanapragasam S, et al. Managing mental health challenges faced by healthcare workers during COVID-19 pandemic. BMJ 2020;368:m1211. https://doi. org/10.1136/bmj.m1211

41. Adams JG, Walls RM. Supporting the healthcare workforce during the COVID-19 global epidemic. JAMA 2020. [Epub ahead of print]. https://doi.org/10.1001/jama.2020.3972

42. Bauchner $\mathrm{H}$, Sharfstein, J. A bold response to the COVID-19 pandemic medical students, national service, and public health. JAMA 2020. [Epub ahead of print]. https://doi. org/10.1001/jama.2020.6166

43. Gallagher TH, Schleyer AM. "We signed up for this!" - student and trainee responses to the COVID-19 pandemic. N Engl J Med 2020. [Epub ahead of print]. https://doi.org/10.1056/ NEJMp2005234

44. Rosenbaum L. Harnessing our uumanity - how Washington's healthcare workers have risen to the pandemic challenge. N Engl J Med 2020. [Epub ahead of print]. https://doi. org/10.1056/NEJMp2007466

45. Kwon YS, Tabakin AL, Patel HV, et al. Adapting urology residency training in the COVID-19 era. Urology 2020. [Epub ahead of print]. https://doi.org/10.1016/j.urology.2020.04.065 